\title{
Long-term functional outcome and satisfaction of patients with hypospadias repaired in childhood
}

\author{
Chris C. Hoag, BSc, MD; Geoff T. Gotto, BSc, MD; Kevin B. Morrison, MSc, MD; \\ Gerald U. Coleman, MD, FRCSC; Andrew E. MacNeily, MD, FRCSC
}

See related article on page 32

\begin{abstract}
Introduction: Potential long-term sequelae of hypospadias and its surgical correction include difficulties in voiding, sexual function, psychosexual adjustment and self-appraisal. These difficulties often evolve long after surgical repair as children grow to adulthood. Despite this, patient-driven data on long-term functional outcomes and satisfaction are limited, leaving the true success of hypospadias surgery essentially unknown. The aim of this study was to address these deficiencies.
\end{abstract}

Methods: We conducted a chart review for all patients operated on by a single urologist from 1981 to 1988. Extensive efforts were made to obtain accurate current address information for patients. A database of patient demographics and pathology, operative details and complications was created. A 22-item questionnaire was mailed to study subjects. Telephone follow-up by an independent research nurse bolstered response rates. Responses from returned questionnaires were pooled and analyzed.

Results: The chart review included 115 patients. Of 100 patients (with address information) who were sent questionnaires, 28 ultimately responded. The chart review group was comparable to groups in other published studies. Despite a slightly higher initial major complication rate $(57.2 \%)$, respondents reported few long-term complications (11\% fistula, 29\% persistent chordee and $10 \%$ stricture) and excellent urinary and sexual functional results. The most common functional complaints were spraying and hesitancy during micturition. Overall, $86 \%$ of patients were satisfied with their surgical result, and $52 \%$ wished they had been provided longer follow-up.

Conclusion: Long-term outcomes data are critical to an honest account of success rates for hypospadias surgery. Obtaining these data remains challenging. In this series, despite high initial complication rates, most patients reported excellent long-term functional results and were quite satisfied with their overall outcome.

CUAJ 2008;2(1):23-31

\section{Introduction}

The implications of hypospadias to the affected child include abnormal voiding patterns and inability to void in the standing position, possible sexual dysfunction, the psychological impact of a genital deformity, potential fertility problems and the prospect of 1 or more corrective surgical procedures as a child. Despite these potentially significant medical and psychosexual sequelae, there is very little published in the literature regarding long-term outcomes for hypospadias patients beyond childhood. A common weakness of the existing literature is that most studies have been based on surgeon impressions of outcome, as opposed to patient satisfaction. ${ }^{1,2}$ In addition, significant contradiction exists in the literature regarding the psychosexual impact of hypospadias and hypospadias repair. ${ }^{3-5}$ Some studies report that sexual development and function are normal, ${ }^{6-8}$ whereas others report less positive results. ${ }^{9-11}$ Some investigators have reported that all patients are satisfied with the cosmetic result, ${ }^{12}$ whereas others have found that $38 \%$ still felt deformed ${ }^{11}$ or that as many as $72 \%$ regarded their penis as abnormal. ${ }^{6}$ Regardless of their bias, most authors agree that these patients need to be followed into adolescence and adulthood to assess patient satisfaction. ${ }^{4-6,11,13,14}$ To our knowledge, there is no Canadian-based literature on this subject, and there are few studies in the world literature that focus on functional outcomes and patient satisfaction as those with hypospadias grow into adulthood. $6,11,14,15$

This study aimed to address these deficiencies in current understanding of the long-term outcomes of hypospadias repair during childhood. This will benefit both surgeons (by providing feedback on the anatomic and functional outcomes of their operations) and patients (by providing a better understanding of their long-term satisfaction after hypospadias repair).

\section{Methods}

This study was conducted in 5 stages: chart review, address identification, questionnaire mail-out, telephone follow-up and data analysis. The study design was approved by the 
British Columbia Children's Hospital institutional ethics review board.

Over the course of 6 months in 2003, all charts for patients who underwent hypospadias operations at the British Columbia Children's Hospital by a single pediatric urologist (G.U.C.) from Jan. 1, 1981, to Dec. 31, 1988, were reviewed. These dates were chosen so that the child would be over age 16 years by the time our questionnaire was mailed out. Data retrieved from the charts included patient name, hospital unique number, provincial health care number, birth date, most recent contact address and phone number, initial grade of hypospadias (according to the Barcat classification $\left.^{16}\right)$, associated anomalies, number of operations (planned and unplanned), date and type of operations, postoperative complications and last known follow-up date. Each patient was assigned a unique identifying number that was used to ensure confidentiality during the data collection phase of the study.

After establishing this database, we made every attempt to obtain accurate current address and telephone information for each patient. We used various sources to obtain this information, including telephone contact, online 411 directory assistance (www.canada411.ca), hospital records and provincial health care records.

A 22-item questionnaire was devised to address 3 main outcomes: operative or technical success, functional success (voiding and sexual function) and patient satisfaction (see Fig. 1 for abridged version). A combination of categorical questions (e.g., yes or no) and visual analogue scales was used. Patients were provided space for free comment and feedback. We assessed the questionnaire for face validity on a group of 15 urology residents.

Questionnaires were mailed to all patients for whom address information was obtained. Each package contained a cover letter explaining the study, a consent form, a uniquely numbered questionnaire and 2 separate stamped and addressed return envelopes (one for the consent form and one for the questionnaire). Participants were directed not to print their names or addresses on the return envelopes or questionnaire. The consent forms and questionnaires were to be mailed back separately to maintain confidentiality in the event of lost mail. All questionnaires were mailed to participants in December 2003. Owing to a clerical error, at least 7 subjects received the abridged 9-question version of the questionnaire that included a section for patient comments.

In an attempt to bolster response rates, participants who had not responded were contacted by telephone over the next 6 months by an independent research nurse and asked whether they would be willing to participate in the study. If they agreed, a study package was mailed to them a second time.

After allowing 12 months for participants to respond, we closed the study and analyzed the data. The main database was analyzed to determine average age at first- and second-stage repairs, average age at last follow-up, initial pathology and complication rates. Participant responses were pooled and summarized.

\section{Results}

In total, we identified 115 patients as having had hypospadias surgery (performed by G.U.C.) between Jan. 1, 1981, and Dec. 31, 1988. All these charts were retrieved and reviewed. The results of the chart review are summarized in Table 1 . The average elapsed time from the date of the last patient follow-up appointment to the time of questionnaire mail-out was 13.7 years. The average patient age at the time of questionnaire mail-out was 20 years (range 16-31 years).

Primary operations were of 3 main types reflecting the commonly used surgical techniques of that era: meatal-based tubes (Mustarde and Broadbent repairs, $19 \%$ ), first-stage chordee correction and Byars flaps (51\%) and meatal advancement (MAGPI repairs, 25\%). One tubularized urethral plate (Duplay procedure) was performed as a primary operation, and 4 procedures were unspecified. Second-stage operations consisted of meatal-based tubes (Mustarde and Broadbent repairs, 72\%) and tubularized ventral penile skin procedures (DennisBrown and Horton-Devine repairs, 26\%). One patient was given a tubularized preputial flap as a second-stage operation. Overall $45 \%$ of patients had a planned 1 -stage procedure, and $53 \%$ had a planned 2-stage procedure (information was not available for 2 patients).

It was not possible to obtain complete addresses for 13 patients, and 2 refused to participate when contacted for their address information. Thus questionnaire packages were mailed to 100 potential participants. During the first 4 months after the 
Operation outcome questions:

1. Circle the number corresponding to the location of the main hole that you now pee out of.

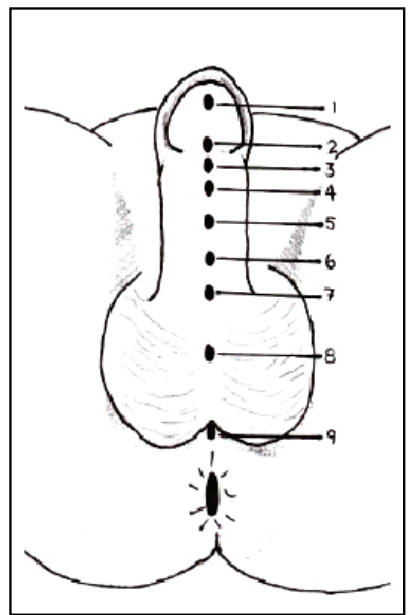

(1) At the tip of the head

(2) Where the head meets the shaft

(3) Near the head

(4) Near the end of the shaft

(5) In the middle of the shaft

(6) Near the start of the shaft

(7) Where the shaft of the penis meets the scrotum

(8) Between the testicles (in the scrotum)

(9) Behind the scrotum

2. Are there any other holes from which urine leaks when you pee? (please circle)

$$
\text { Yes / No }
$$

- If you answered 'yes' above, please indicate how many additional holes there are (not including the main hole indicated in question 1)? (please circle)

3. Does your penis curve downwards? (please circle)

$$
\begin{array}{llllll}
1 & 2 & 3 & 4 & 5 & 6 \text { or more }
\end{array}
$$

Yes / No

- If you answered 'yes' above, please indicate the degree of curvature below by checking the most appropriate box
$\square$ 0-44 degrees
45-89 degrees
$90+$ degrees

\section{Functional outcome questions:}

4. Are you or have you ever been sexually active? (please circle):

Yes / No

- If you answered 'yes' above, please indicate below how old you were when you were first sexually active?

Age:

5. Are you able to engage in penetrative intercourse? (please circle)

Yes / No

6. Are you able to pee in a toilet while standing? (please circle)

Yes / No

Patient satisfaction outcome questions:

7. Overall, please indicate below your level of satisfaction with the appearance of your penis (circle number).
Very unsatisfied

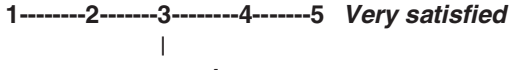

8. Overall, please indicate below your level of satisfaction with the sexual function of your penis (circle number).

Very unsatisfied

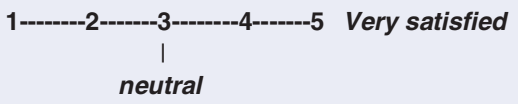

9. Overall, please indicate below your level of satisfaction with your ability to urinate.

Very unsatisfied

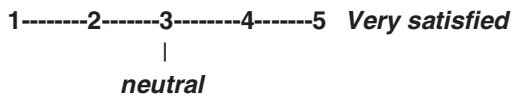

COMMENTS:

Fig. 1. Long-term hypospadias surgery outcome questionnaire (abridged version). 
mail-out, 14 participants consented and returned their completed questionnaires; 11 questionnaires were returned unopened and marked "return to sender." After the research nurse contacted the nonrespondents by telephone, another 14 consented and returned their completed questionnaires. Thus 15 patients never received packages (either there was no address information for them or they refused consent), while 72 patients never responded and 28 patients consented and returned their completed questionnaires. The characteristics of these 3 groups are summarized in Table 1.

Of the 28 respondents, 7 received an abridged 9-question version of the questionnaire as a result of a clerical error. The responses to each of the questions are summarized in Table 2 and Figure 2. Of those who complained of chordee, $75 \%$ indicated that it was minor $\left(<45^{\circ}\right)$.

Fourteen respondents provided comments, including 5 of those who received the abridged questionnaire. Three were expressions of gratitude for the care they had received, 3 were clarifications of questionnaire responses, 7 were expressions of angst or frustration with outcomes (spraying, penis size, number of operations, single hair in urethra, scars and embarrassment), and 1, the final comment, was that of a patient's mother who described her son's nightmares of men and women in scrubs for several years after his surgery.

\section{Discussion}

\section{Chart review findings}

According to our chart review data, our patient population appears to be comparable to populations in the wider hypospadias literature. We found that the distribution of anterior (54\%), middle $(14 \%)$ and posterior (30\%) hypospadias was similar to distributions in other authors' series. . $^{8,11,15,17,18}$ The degree of chordee is universally poorly reported in the literature, making comparison of this aspect of initial patient pathology difficult. In our series, the average age at first operation was 2 years, which was early in comparison with other studies of that time period, ${ }^{11,13,15,17,19}$ but which now falls closer to the accepted optimal time period for initial repair. ${ }^{20}$ Associated anomalies appeared concordant with other reports. ${ }^{17,21}$

Reported complication rates from other studies of that time period fall within the range of $50 \% .{ }^{11,13,15}$ We found a slightly higher overall major complication rate in our single-surgeon study $(58.3 \%)$. Fistula rates $(55.7 \%)$ were high, although within the range of reported outcomes. ${ }^{6,13,18,22}$ Minor complications included isolated perioperative urinary infections and balanitis, urethral stent extrusion, patulous meatus and minor excess skin deformity.

\section{Long-term follow-up questionnaire findings}

Because of the subject of this study and the significant elapsed time since last follow-up (13.7 yr), we expected from the outset that we would have a low response rate. With telephone follow-up, $28 \%$ of subjects who were mailed a questionnaire eventually responded. It is quite likely that, despite our best efforts, a significant proportion of our subject address data was outdated, and this response rate likely underestimates the true response rate for the number of intended subjects who actually did receive the questionnaire package.

Few published studies have followed hypospadias patients into adulthood. Only 4 have focused (to a greater or lesser degree) on patient-reported long-term functional outcomes and satisfaction, ${ }^{11,14,15,19}$ whereas most others have focused on surgeon-assessed outcomes. Patient response rates range from $23.4 \%{ }^{8}$ to $87 \%,{ }^{10}$ and many authors comment on the logistical difficulty of tracking these patients to early adulthood. Our response rate of $28 \%$ falls within the low end of this range. Contributing factors to the difficulty with followup that are unique to our study included length of time to follow-up, the huge catchment area served by the BC Children's Hospital (the entire province of 365000 square miles and 4.3 million residents), the geographical remoteness of most of the communities served and the inherent mobile nature of the youth in this province (to find employment or pursue further education).

We believe that the best judge of the longterm success of hypospadias repairs is the patient himself, who can best assess functional outcomes and satisfaction. It has been demonstrated that surgeon and patient impressions of outcome are often discordant. ${ }^{3}$ Despite the higher initial complication rate indicated by our chart review data (57.2\% of respondents had major complications), our questionnaire respondents faired remarkably 
Table 1: Summary of group characteristics

\begin{tabular}{|c|c|c|c|c|}
\hline \multirow[b]{2}{*}{ Characteristic } & \multirow[b]{2}{*}{$\begin{array}{l}\text { Total chart review, } \\
\qquad n=115\end{array}$} & \multicolumn{2}{|c|}{ Group; no. (and \%)* } & \multirow[b]{2}{*}{$\begin{array}{l}\text { No mail-out } \\
\text { sent, } n=15\end{array}$} \\
\hline & & $\begin{array}{l}\text { Respondents, } \\
n=28\end{array}$ & $\begin{array}{l}\text { Nonrespondents, } \\
\quad n=72\end{array}$ & \\
\hline Average age at first $O R, y r$ & 1.96 & 1.95 & 1.92 & 2.18 \\
\hline No. who had 2 nd-stage repair & $65(56.6)$ & $18(64.3)$ & $40(55.6)$ & $7(46.7)$ \\
\hline Average age at 2 nd stage $O R$ & 3.46 & 3.35 & 3.37 & 4.3 \\
\hline Average age at last follow-up & 6.26 & 7.24 & 5.86 & 6.34 \\
\hline Average no. of total OR's & 3.0 & 3.6 & 3 & 2.4 \\
\hline No. who had a fistula repair & $56(48.7)$ & $12(42.9)$ & $36(50.0)$ & 8 (53.3) \\
\hline Average no. of fistula repairs & 1.95 & 2.75 & 1.81 & 1.38 \\
\hline \multicolumn{5}{|l|}{$\begin{array}{l}\text { Initial degree of hypospadias } \\
\text { (Barcat) }\end{array}$} \\
\hline Anterior & $62(53.9)$ & $13(46.4)$ & $41(56.9)$ & $8(53.3)$ \\
\hline Middle & $16(13.9)$ & $6(21.4)$ & $8(11.1)$ & $2(13.3)$ \\
\hline Posterior & $35(30.4)$ & $8(28.6)$ & 23 (31.9) & $4(26.7)$ \\
\hline Not recorded & $2(1.7)$ & $1(3.6)$ & 0 & $1(6.7)$ \\
\hline \multicolumn{5}{|l|}{ Initial degree of chordee } \\
\hline None & $27(23.5)$ & $6(21.4)$ & $16(22.2)$ & 5 (33.3) \\
\hline Mild $\left(<45^{\circ}\right)$ & $23(20)$ & 5 (17.9) & $16(22.2)$ & $2(13.3)$ \\
\hline Moderate to severe $\left(>45^{\circ}\right)$ & $55(47.8)$ & $14(50.0)$ & $35(48.6)$ & $6(40.0)$ \\
\hline Present, severity not given & $7(6.1)$ & $3(10.7)$ & $4(5.6)$ & 0 \\
\hline Not recorded & $3(2.6)$ & 0 & $1(1.4)$ & $2(13.3)$ \\
\hline Associated GU anomalies & $41(35.7)$ & $11(39.3)$ & $25(34.7)$ & 5 (33.3) \\
\hline Renal & $9(7.8)$ & $4(14.3)$ & $5(6.9)$ & 0 \\
\hline VUR & $2(1.7)$ & $1(3.6)$ & 0 & $1(6.7)$ \\
\hline Penoscrotal & $19(16.5)$ & $6(21.4)$ & $10(13.9)$ & $3(20.0)$ \\
\hline Hydroceles/hernias & $13(11.3)$ & $3(10.7)$ & $10(13.9)$ & 0 \\
\hline UDT & $11(9.6)$ & $4(14.3)$ & $5(6.9)$ & $2(13.3)$ \\
\hline Suspected syndromes & $9(7.8)$ & $4(14.3)$ & $4(5.6)$ & $1(6.7)$ \\
\hline Complications & $79(68.7)$ & $20(71.4)$ & $49(68.1)$ & $10(66.7)$ \\
\hline None & $36(61.3)$ & $8(28.6)$ & 23 (31.9) & $5(33.3)$ \\
\hline Minor only & $12(10.4)$ & $4(14.3)$ & $8(11.1)$ & 0 \\
\hline Fistulas & $64(55.7)$ & $15(53.6)$ & 39 (54.2) & $10(66.7)$ \\
\hline Other major & $3(2.6)$ & $1(3.6)$ & $2(2.8)$ & 0 \\
\hline \multicolumn{5}{|l|}{ First procedures performed } \\
\hline Meatal-based tube & $22(19.0)$ & $5(18.0)$ & $15(21.0)$ & $2(13.0)$ \\
\hline $\begin{array}{l}\text { Chordee correction and } \\
\text { Byars flaps }\end{array}$ & $59(51.0)$ & $17(61.0)$ & $36(50.0)$ & $6(40.0)$ \\
\hline Meatal advancement & $29(25.0)$ & $5(8.0)$ & $19(26)$ & $5(33.0)$ \\
\hline Tubularized urethral plate & $1(1.0)$ & 0 & $1(4.0)$ & 0 \\
\hline Unspecified & $4(3.5)$ & $1(3.6)$ & $1(4.0)$ & $2(13.0)$ \\
\hline \multicolumn{5}{|l|}{ 2nd procedures performed } \\
\hline Meatal-based tube & $47(72.0)$ & $14(78.0)$ & $28(70.0)$ & $5(71.0)$ \\
\hline $\begin{array}{l}\text { Tubularized ventral penile } \\
\text { skin }\end{array}$ & $17(26.0)$ & $3(17.0)$ & $12(30.0)$ & $2(29.0)$ \\
\hline Tubularized preputial flap & $1(1.5)$ & $1(5.0)$ & 0 & 0 \\
\hline Not applicable & 50 & 10 & 32 & 8 \\
\hline
\end{tabular}


well over the long term. Of 26 respondents, 24 stated that their main meatus was at the corona or glans, $11 \%$ reported an ongoing fistula, and $10 \%$ recollected having had a urethral stricture.
The most common operational outcome complaint among respondents was some degree of persistent chordee $(29 \%)$, most (6 of 8 ) of which was minor $\left(<45^{\circ}\right)$. The other 2 respondents

\begin{tabular}{|c|c|c|c|c|c|}
\hline \multirow[b]{2}{*}{ Question } & \multicolumn{5}{|c|}{ Group; no. (and \%) } \\
\hline & $\begin{array}{l}\text { No. } \\
\text { asked }\end{array}$ & Yes & No & $\begin{array}{l}\text { Don't } \\
\text { know }\end{array}$ & $\begin{array}{l}\text { Didn't } \\
\text { answer }\end{array}$ \\
\hline \multicolumn{6}{|l|}{ Operation outcome questions } \\
\hline $\begin{array}{l}\text { 2. Are there any other holes from } \\
\text { which urine leaks when you pee? }\end{array}$ & 28 & $3(11)$ & $25(89)$ & - & - \\
\hline $\begin{array}{l}\text { 3. Does your penis curve } \\
\text { downwards (while flaccid or erect)? }\end{array}$ & 28 & $8(29)$ & $18(64)$ & - & $2(7)$ \\
\hline $\begin{array}{l}\text { 4. Since your last operation have } \\
\text { you ever had a urethral stricture } \\
\text { (a narrowing of the urination tube)? }\end{array}$ & 21 & $2(10)$ & $7(33)$ & $12(57)$ & - \\
\hline \multicolumn{6}{|l|}{ Functional outcome questions } \\
\hline $\begin{array}{l}\text { 5. Is your stream straight when you } \\
\text { pee? }\end{array}$ & 21 & $16(76)$ & $5(24)$ & - & - \\
\hline $\begin{array}{l}\text { 6. Do you experience spraying } \\
\text { when you pee? }\end{array}$ & 21 & $11(52)$ & $10(48)$ & - & - \\
\hline $\begin{array}{l}\text { 7. Do you experience difficulty } \\
\text { starting your stream when you try } \\
\text { to pee? }\end{array}$ & 21 & $11(52)$ & $10(48)$ & - & - \\
\hline 8. Do you have to strain to pee? & 21 & $3(14)$ & $18(86)$ & - & - \\
\hline $\begin{array}{l}\text { 9. Do you feel you are able to } \\
\text { completely empty your bladder } \\
\text { when you pee? }\end{array}$ & 21 & $18(86)$ & $3(14)$ & - & - \\
\hline $\begin{array}{l}\text { 10. Have you ever been unable to } \\
\text { pee and, as a result, required a } \\
\text { catheter in order to empty your } \\
\text { bladder? }\end{array}$ & 21 & 1 (5) & $20(95)$ & - & - \\
\hline $\begin{array}{l}\text { 12. Since your last operation, have } \\
\text { you ever had a confirmed bladder } \\
\text { infection for which you were } \\
\text { prescribed antibiotics? }\end{array}$ & 21 & $4(19)$ & $17(81)$ & - & - \\
\hline $\begin{array}{l}\text { 13. Are you able to pee in a toilet or } \\
\text { urinal while standing? }\end{array}$ & 28 & $26(93)$ & $2(7)$ & - & - \\
\hline $\begin{array}{l}\text { 14. Have you had penetrative } \\
\text { sexual intercourse? }\end{array}$ & 28 & $17(61)$ & $11(39)$ & - & - \\
\hline $\begin{array}{l}\text { 15. Do you have pain during sexual } \\
\text { intercourse? }\end{array}$ & 21 & $1(5)$ & $17(81)$ & - & $3(14)$ \\
\hline $\begin{array}{l}\text { 16. Are you currently able to have } \\
\text { sexual intercourse? }\end{array}$ & 28 & $25(89)$ & $1(4)$ & - & $2(7)$ \\
\hline $\begin{array}{l}\text { 17. Do you experience any } \\
\text { problems with ejaculation? }\end{array}$ & 21 & 1 (5) & $20(95)$ & - & - \\
\hline \multicolumn{6}{|l|}{ Patient satisfaction outcome questions } \\
\hline $\begin{array}{l}\text { 21. Overall, are you satisfied with } \\
\text { the result of your hypospadias } \\
\text { operation(s)? }\end{array}$ & 21 & $18(86)$ & $2(10)$ & - & $1(5)$ \\
\hline $\begin{array}{l}\text { 22. Would you have preferred } \\
\text { longer follow-up after your } \\
\text { hypospadias operation(s)? }\end{array}$ & 21 & $11(52)$ & $9(43)$ & - & 1 (5) \\
\hline$-=$ no data. & & & & & \\
\hline
\end{tabular}


indicated an intermediate degree of chordee $\left(45-90^{\circ}\right)$. A similar long-term follow-up study reported a $20 \%$ rate of residual chordee $>30^{\circ},{ }^{11}$ which is within the range of our findings. Interestingly, in the same study, only $30 \%$ of those patients found degree of chordee to be a major physical handicap. ${ }^{11}$ In our study, all patients with residual chordee had been sexually active (5) or felt that they were capable of sexual activity (3), and only 1 of these subjects (who had a minor degree of residual chordee) experienced pain with intercourse. One of the 2 patients with intermediate chordee had been sexually active without reported pain.

Functional outcomes in terms of micturition were also encouraging. Most study subjects voided with a moderate or strong stream, had no deviation of their stream, were able to void without

1. Circle (on diagram) the number corresponding to the location of the main hole

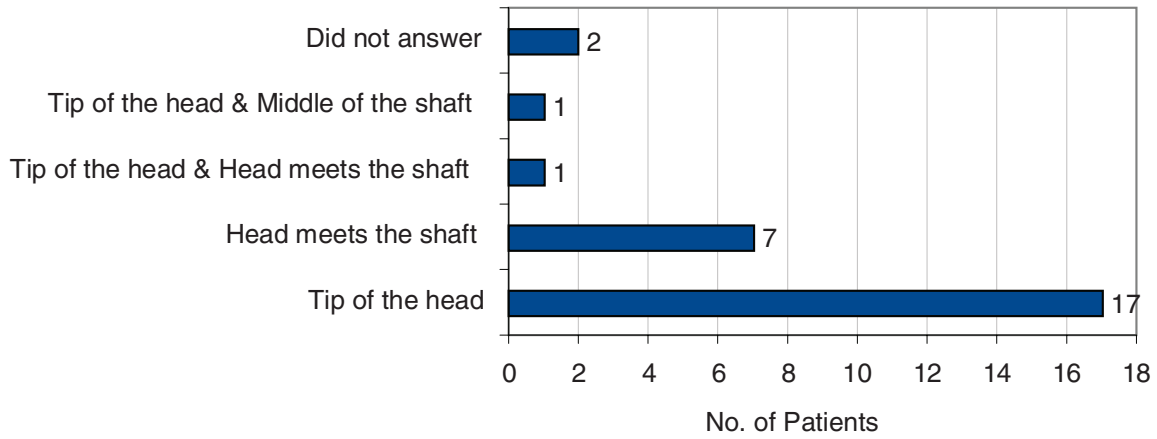

11. On the scale below, please grade the force of your stream.

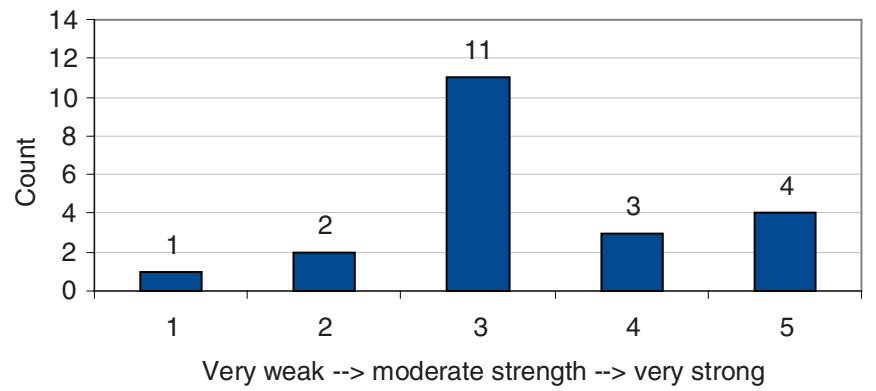

19. Overall, please indicate below your level of satisfaction with the sexual function of your penis.

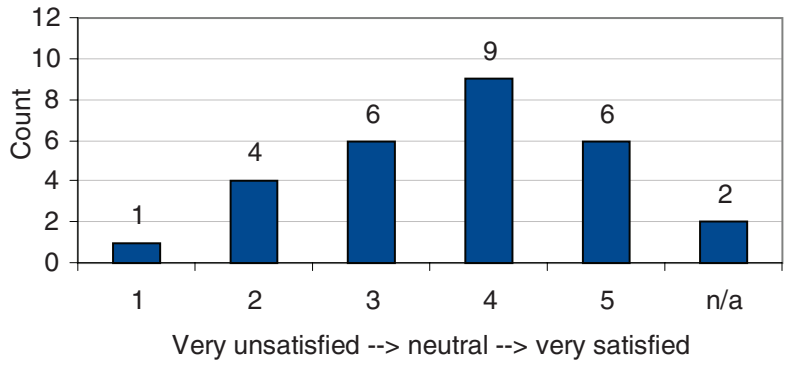

18. Overall, please indicate below your level of satisfaction with the appearance of your penis.

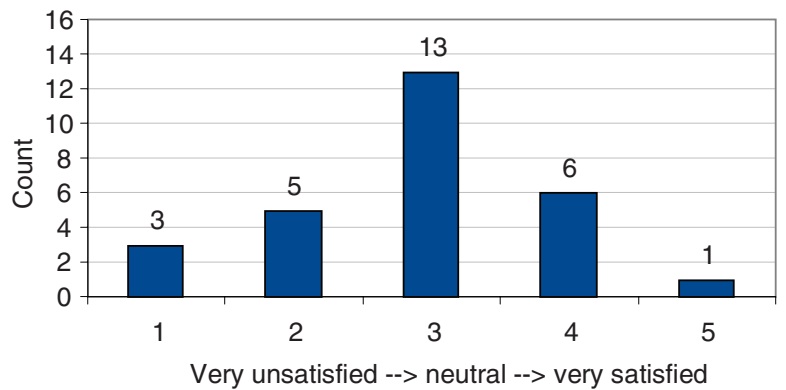

20. Overall, please indicate below your level of satisfaction with your ability to urinate.

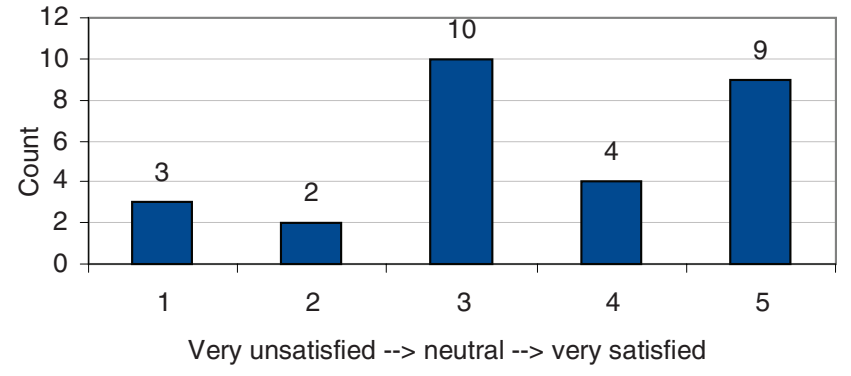

Fig. 2. Responses to question 1 and visual analogue questions. 
straining and felt that they emptied their bladders well; $93 \%$ were able to void in the standing position. Strangely, although few obstructive lower urinary tract symptoms were reported, $52 \%$ of subjects reported difficulty starting their streams when voiding. Without interviewing subjects further, it is difficult to explain this finding, although identical findings of hesitancy in the absence of anatomic obstruction were reported by van der Werff and Ultee. ${ }^{14}$ The most common micturition complaint was spraying (52\%) which is consistent with other long-term outcome studies. ${ }^{6,10,11,15}$ A minority of respondents (5/28) indicated overall dissatisfaction with their ability to void.

The average age of respondents was 20 years, and $61 \%$ had had sexual intercourse at some point before receiving our questionnaire, which is consistent with the findings in similar studies of hypospadias patients as young adults. ${ }^{6,8,11}$ Multiple studies have demonstrated that those with hypospadias have delayed sexual milestones (emotional intimacy, physical intimacy and sexual intercourse). $4,5,7,10,23,24$ However, they do not appear to differ significantly from normal men in terms of sexual functioning (erection quality, ejaculation, satisfaction and pain). ${ }^{4,8,10}$ These findings also appear to be reflected in our study, in which all but 1 respondent denied difficulty or pain with sexual intercourse or ejaculation and most (15/28, with 6 others being "neutral") indicated satisfaction with their sexual functioning. Finally, most respondents were "neutral" about their satisfaction regarding the appearance of their penis. This variation in genital appraisal is reflected elsewhere in the literature. ${ }^{6,11,12}$ Further, the low positive genital appraisal may explain their apparently delayed sexual debut, as suggested by Mureau and colleagues., ${ }^{4,5}$ Two of our respondents who provided comments corroborated this suggestion by indicating that anxiety over the appearance of their penis had delayed their first sexual experience.

Overall, most respondents (86\%) were satisfied with the result of their hypospadias surgery. Respondents who received the abridged questionnaire were not asked about their "overall" satisfaction; however, they were asked about their level of satisfaction in the specific realms of ability to urinate, sexual function and cosmesis. Of these 7 respondents, 3 responded with scores of 1 or 2 on the visual analogue scales for these individual facets of satisfaction. Three of these patients also provided comments indicating frustration with their outcomes, particularly in the realm of urination and self-consciousness. It is impossible to say how these 7 respondents would have answered the "overall" satisfaction question, but extrapolating from the data available (that 3 were dissatisfied) still yields an overall satisfaction rate of $79 \%$ (22/28).

Despite the favourable overall satisfaction rates, many $(52 \%)$ wished they had had longer followup. This desire for longer follow-up through adolescence has been documented by several other authors ${ }^{3,15,23}$ citing delayed complications, increased adolescent anxiety, poor body image and patients' misunderstanding of their medical history. ${ }^{6,11}$ Patients have been shown to be reluctant to seek further medical advice despite significant distress. ${ }^{11}$ Several authors have therefore recommended routine surgeon-initiated follow-up until age 15 years or later. ${ }^{4-6,11,13,14}$ We echo this recommendation; in the impending era of electronic medical records (with automated follow-up routines), initiating these follow-up appointments 10-15 years postrepair will become increasingly feasible.

One of the potential limitations of this study is response bias. It is possible that patients' outcomes (positive or negative) affected their likelihood of responding to our questionnaire. Another limitation of this study is the possibility of subjective misinterpretation of the questionnaire by study participants. For example, the query regarding chordee in both the flaccid and erect states could have been misinterpreted by some respondents. Finally, the inherent difficulty in interpretating long-term hypospadias studies is the applicability of the findings to today's operations. As in all other long-term studies, the operations performed on our study subjects are outmoded and have been replaced by newer techniques that are thought to be superior but have yet to stand the rigorous test of time. Nonetheless, long-term studies (especially those based on patient response) are critically important to highlighting the key outcome issues that continue to hamper or dissatisfy hypospadias patients into adulthood.

\section{Conclusion}

Long-term follow-up data are limited for adult hypospadias patients who had reparative 
surgery in childhood, particularly with regard to patient-reported functional outcomes and satisfaction. Patient-reported outcomes are of paramount importance (outweighing surgeon-assessed outcomes) in assessing the success of hypospadias surgeries. Many patients report hesitancy in seeking medical attention as they mature through adolescence, despite significant distress, making surgeon-initiated long-term follow-up critically important. Our series has demonstrated positive long-term outcomes in adult hypospadias patients repaired as children. Patients were satisfied with their overall surgical result and function and appeared to be experiencing minimal long-term voiding and sexual sequelae. The most common functional complaints were hesitancy and spraying during micturition. Because hypospadias surgery is a constantly evolving art, long-term studies (into adulthood) will continue to be important and will need to be repeated for each new procedure developed if surgeons are to continue to provide an honest and meaningful account of their results.

From the Department of Pediatric Urology, University of British Columbia, Vancouver, BC Acknowledgement: Statistical analysis by AnalysisWorks Inc., Vancouver, BC.

This article has been peer reviewed.

Competing interests: None declared.

\section{References:}

1. Jayanthi VR, McLorie GA, Khoury AE, et al. Functional characteristics of the reconstructed neourethra after island flap urethroplasty. J Urol 1995;153:1657-9.

2. Garibay JT, Reid C, Gonzalez R. Functional evaluation of the results of hypospadias surgery with uroflowmetry. J Urol 1995;154:835-6.

3. Mureau MA, Slipper FM, Slob AK, et al. Satisfaction with penile appearance after hypospadias surgery: the patient and surgeon view. J Urol 1996;155:703-6.

4. Mureau MA, Slijper FM, van der Meulen JC, et al. Psychosexual adjustment of men who underwent hypospadias repair: a norm-related study. J Urol 1995;154:1351-5.
5. Mureau MA, Sliper FM, Nijman RJ, et al. Psychosexual adjustment of children and adolescents after different types of hypospadias surgery: a norm-related study. I Urol 1995;154:1902-7.

6. Sommerlad BC. A long-term follow-up of hypospadias patients. Br J Plast Surg 1975;28:324-30.

7. Avellan L. The development of puberty, the sexual debut and sexual function in hypospadiacs. Scand J Plast Reconstr Surg 1976;10:29-44.

8. Kenawi MM. Sexual function in hypospadiacs. Br J Urol 1975;47:883-90.

9. Farkas LG, Hynie J. Aftereffects of hypospadias repair in childhood. Postgrad Med 1970; 47:103-5.

10. Berg R, Svensson J, Astrom G. Social and sexual adjustment of men operated for hypospadias during childhood: a controlled study. J Urol 1981;125:313-7.

11. Bracka A. A long-term view of hypospadias. Br J Plast Surg 1989;42:251-5.

12. Maier WA, Tewes $G$. Sexual function after operations for hypospadias according to Ombredanne. Prog Pediatr Surg 1984;17:79-82.

13. Nuininga JE. DE Gier RP, Verschuren R, et al. Long-term outcome of different types of 1-stage hypospadias repair. J Urol 2005;174:1544-8; discussion 1548.

14. van der Werff JF, Ultee J. Long-term follow-up of hypospadias repair. Br J Plast Surg 2000;53:588-92.

15. Aho MO, Tammela OK, Tammela TL. Aspects of adult satisfaction with the result of surgery for hypospadias performed in childhood. Eur Urol 1997;32:218-22.

16. Barcat J. Current concepts in treatment. In: Horton CE, editor. Plastic and reconstructive surgery of the genital area. Boston: Little, Brown;1973, p. 249-63.

17. Wu WH, Chuang JH, Ting YC, et al. Developmental anomalies and disabilities associated with hypospadias. J Urol 2002;168:229-32.

18. Marrocco $G$, Vallasciani $S$, Fiocca $G$, et al. Hypospadias surgery: a 10-year review. Pediatr Surg Int 2004;20:200-3.

19. Lam PN, Greenfield SP, Williot P. 2-stage repair in infancy for severe hypospadias with chordee: long-term results after puberty. J Urol 2005;174:1567-72; discussion 1572.

20. Timing of elective surgery on the genitalia of male children with particular reference to the risks, benefits, and psychological effects of surgery and anesthesia. American Academy of Pediatrics. Pediatrics 1996;97:590-4.

21. Retik AB, Borer JG. Hypospadias, In: Retik AB, Vaughan ED, Wein AJ, et al., editors. Campbell's urology. 8th ed. Philadelphia: Saunders; 2002. p. 2291.

22. Nelson CP, Bloom DA, Kinast R, et al. Long-term patient reported outcome and satisfaction after oral mucosa graft urethroplasty for hypospadias. J Urol 2005;174:1075-8.

23. Aho MO, Tammela OK, Somppi EM, et al. Sexual and social life of men operated in childhood for hypospadias and phimosis. A comparative study. Eur Urol 2000;37:95100; discussion 101.

24. Svensson J, Berg R, Berg G. Operated hypospadiacs: late follow-up. Social, sexual, and psychological adaptation. J Pediatr Surg 1981;16:134-5.

Correspondence: Dr. Andrew E. MacNeily, Head of Department of Pediatric Urology, K0-134 BC Children's Hospital, 4480 Oak St., Vancouver BC V6H 3V4; amacneily@cw.bc.ca 